\title{
Re-conceptualizing the Jordanian Art Education Curricula: Suggested Entries for Teaching Discipline-Based Art Education Theory
}

\author{
Bassam Al-Radaideh ${ }^{1}$, Raed Al-Share ${ }^{2} \&$ Asem Obidat $^{3}$ \\ ${ }^{1}$ College of Fine Arts, Yarmouk University, Jordan \\ ${ }^{2}$ Faculty of Engineering Technology, Al-Balqa Applied University, Jordan \\ ${ }^{3}$ College of Fine Arts \& Design, University of Sharjah, UAE \\ Correspondence: Bassam Al-Radaideh, College of Fine Art, Yarmouk University, Jordan. E-mail: \\ bassamr20@hotmail.com
}

Received: March 1, 2019

Accepted: March 29, 2019

Online Published: April 6, 2019

doi:10.5539/ach.v11n2p26

URL: https://doi.org/10.5539/ach.v11n2p26

\begin{abstract}
The curricula of art education in the elementary and secondary schools of Jordan is limited to teaching technical skills for making art, and students did not receive tangibleeducation about history of art, aesthetic, and critical aspects of art. This study identified the theory of Discipline-Based Art Education (DBAE) and its significance in teaching art, and it provided suggestions for teaching history of art, criticism, aesthetic and artistic production. Furthermore, the study justified the possibility of implementing the DBAE approach in Jordan art education curricula. The research revealed that DBAE theory improved and elevated art education to a new level because the four disciplinary content area played a significant role in the development of essential knowledge and skills in the art such as developing the creativity, appreciation, understanding and learning about the role and function of art in human civilization. The study recommends to include the components of DBAE to art education instruction in Jordanian curricula.
\end{abstract}

Keywords: Jordanian Art Education, History of Art, Aesthetics, Art Curricula, Discipline-Based Art Education, Learning Outcomes Students.

\section{Introduction}

Discipline-Based Art Education (DBAE) is one of the most popular trends in art education in the United States of America and most of European countries, and it has attracted interest among many scientists and art educators both inside and outside the this countries. However, despite this proliferation, this theory is still under constant testing and evaluation. Since the emergence of this approach in the mid-eighties, and those at the Getty Center are keen to remain under continuous evaluation to avoid deficiencies and imperfections that prevent its optimal application (Eisner, 1988).

In the early 1960s, Bruner presented his idea that every science must derive from its structure of discipline as a basis for teaching and learning, which prompted Barkan to adopt Brunner's ideas and turn them into facts and ideas for teaching art education. Then, Eisner came up with a curriculum for art education based on the source of knowledge as a basis for art education, which is concerned with the history of art, artistic production, art criticism, and aesthetics (Delacruz \& Dunn, 1996). This theory was called Discipline-Based Art Education (DBAE), which is the current research subject that explains the emergence of this theory, its evolution and the bases it adopted. The research also reviews the most important studies that written about it, the extent to which they can be applied in schools, and included in the curricula of art education in Jordan at different levels of education. In addition to showing the positives aspects of this theory and its impact on teaching and learning.

\section{Research Problem}

The curricula of art education in Jordan are almost devoid of contemporary artistic trends or theories. Which led to the lack of students' knowledge of the importance of art education as a critical factor in the development of thinking experiences, innovations, and skills that promote a broader and more comprehensive understanding of other sciences which resulted in:

1) Students do not know the history of art, that records the heritage, culture, and the historical civilization, and 
also they do not recognize the ideas and culture of other nations.

2) Students lack knowledge about criticism that leads to critical thinking, the issuance of the decision, and governance, and accepts the opinion and the opinion of others.

3) Students do not feel the value of beauty, which leads to environmental, aesthetic appreciation, and promotes good citizenship.

4) The decline of artistic production, which connected to creativity and innovation and acquisition of skills in students.

Therefore, this study aims to identify the theory of Discipline-Based Art Education in art education curriculum based on the organized cognitive trend, which focuses on the fundamental role of the history of art, art criticism, aesthetics and artistic production in teaching art education in schools and the feasibility of applying this theory to schools.

\subsection{The Objective of This Study}

This research aims to identify the Discipline-Based Art Education (DBAE) in teaching art education and its applicability in Jordanian schools. In addition to clarifying the basics of this theory and provide suggestions as a preface for teaching art history, criticism, aesthetics and artistic production through art education curriculum.

\subsection{Research Importance}

This research derives its importance through:

1) Identifying the concept of art education based on DBAE theory, and the extent of its applicability in Jordanian art education curriculum.

2) It is concerned with the theoretical and applied aspects of teaching art education.

3) Improving the teaching process through teaching higher mental levels, such as critical thinking, analysis, interpretation, judgment, criticism, and decision-making, rather than focusing on teaching artistic production only.

4) Encouraging students for innovation and creativity based on contemplative knowledge.

5) The need for studies to cover the shortage of teaching art education in schools, and keeping up with the developments in art education methods, strategies, and techniques.

6) Contribution to the development of art education curricula to suit our society needs and our educational environment.

7) Helping those who are interested in teaching art education to learn about the DBAE.

\subsection{Research Questions}

To do so, the following four research questions will be addressed:

1) What are the theory of DBAE and its significance in art education?

2) What is the significance of teaching the four trends of DBAE theory in art education?

3) What is the suggested DBAE learning entries?

4) What is the possibility of teaching the DBAE through Jordan art curricula?

\subsection{Methodology}

The researchers adopted the analytical, descriptive method in studying the philosophical trend of this theory through the emergence of this approach, its critique and the extent of their application in the Jordanian Art Education Curricula.

\section{The Discipline-Based Art Education (DBAE)}

In the past and until the present, the teaching method of art education was how to teach students the techniques of drawing and painting, how to color things and how to make handcrafts ...etc. These art methods continued until a very recent time (and still in some educational environments). When the DBAE theory emerged the methods of teaching changed to a concept that concerned with the overall development of the student regarding developing the cognitive, artistic skills and emotional aspects according to a structured curriculum that can be taught and learned.

The theory of DBAE in teaching art education is one of the most prominent modern concepts in the field of teaching art education in western curricula, especially in the United States of America. It is a comprehensive approach to teaching and learning art education to educate. DBAE supports a diminished emphasis on studio 
instruction and instead promotes education across four disciplines within the arts: aesthetic, art criticism, art history, and art production.

DBAE theory was developed primarily by a group of Western are teachers, to suit the need to transfer knowledge and artistic experiences to students in public education. The first definition of this theory credited to William Dwaine Greer, who wrote a paper about it in 1984, in which he announced the nature and characteristics of this theory, which dates back to the 1960s, and he calls it discipline-based art education (Greer, 1984)

Following its foundation in 1983, the Getty Education Center adopted the ideas of art educators leaders who had been calling for a more comprehensive, and multifaceted approach to art education. Therefore, they advocate DBAE as an effective means by which to help students experience the visual arts in a variety of ways. Getty Education Institute programs believe that visual arts should be an essential part of every child's education because through the creation of arts and the inquiry into the art meaning are primary means through which we understand human's experiences and transmit the cultural values (Delacruz \& Dunn, 1996).

This theory was initially expected to enable the learner to be exposed to a variety of knowledge and experience in a range of different sciences through art content such as humanities, sociology, history, philosophy, archeology, communication technology, and other general knowledge, by focusing on studying the DBAE that are closely related to art production, criticism, art history and aesthetic. Educators, who integrate content from the four disciplines in the DBAE approach, aim, to provide skills, knowledge, and understanding that enabled students to have a rich experience with art.

The pioneers of art education have confirmed through several conferences held in the United States that these four disciplines of DBAE will enable the art education teachers to teach students the knowledge, skills, and the experiences that work on developing the creativity, appreciation, understanding the significance of artwork and its connection to the professional level and learning about the role and function of arts in human civilizations (Agustin, 2016). Furthermore, the pioneers emphasized that the adoption of a discipline-based art education approach to teaching art education will make the learner able to understand and evaluate the artistic work in different contexts such as moral, philosophical, social, economic, religious, emotional and creative skills.

Among the most important conferences is Penn State University conference, which was held in 1965 and discussed the idea that the education can be done through art and that art is a system or an independent course that can be taught separately from other subject's contents (Efland, 1987). One of the most leadingresearchers who presented a paper at that conference, and became one of the founders of the DBAE theory as a subject, Eliot Eisner. In his article, Eisner explained that until that date art education was taught, by only artistic production, and that it is necessary to find a new approach to art education that is flexible and fruitful (Eisner, 1988). Other leading scholars at Penn State University conference, Emmanuel Barkan, in which he concluded that there is an urgent need for a theory that could be performed in teaching arts, and that approach should contain the artist' work and the ideas of those who write in aesthetics and criticism (Efland, 1987).

Clark \& Zimmerman (1978), are among the other researchers who had efforts about the same subject. They tried to prove that the roles and activities of the artist, the art critic, the historian and the beauty scientist need to be integrated into the production of models to improve the expected output of teaching programs. Although many scholars recognized the need to train the child to be an artist child, they did not provide an organized and sequential method to do so.

Usually judging an artwork include describing, praising or critique the artwork. We try to prove first if that work is an art. This verbal explanation takes place in drawing while students work on their art projects. As the case of the student's participation in the history of art, or in art criticism. However, the discussion about the art focuses on the areas of history, criticism, and the philosophy. These fields affect the artistic production of the students and the level of creative performance. (Hassan, Noor, \& Omar, 2014).

The results of these opinions led to creating a methodological content that can be taughtby considering the fundamental traits of the content such as:

1) The educational content consists of four art disciplines.

2) Encourage students for exploration, discovery, creativity and doing researches through the four art fields practices.

3) To develop the cognitive, skills and emotional aspects of the students. 
4) The four art disciplines work through the cognitive-behavioral theory to promote creativity, imagination, critical thinking and developing the students' abilities and skills to learn about the techniques of handling raw materials and artistic tools.

In 1983, the Getty Center introduced a developed curriculum for art education based on the following facts:

1) The art education considered one of the structured knowledge fields.

2) The integration of the four disciplinesin the curriculum to create an integrated understanding of art within the framework of art education.

3) Define the objectives of the art education and reorganize it systematically.

4) Design a sequential educational unitsplan for the four fields of arts with taking into account the psychological logic in the curriculum.

5) Define the evaluation and assessment methods.

The following sections will discuss the significance of each discipline in the DBAE theory, as well as learning outcomes, objectives, and teaching entries. Also, it will present the possibilities of implementing the DBAE theory in Jordan art education curricula.

\section{Art Production}

The art production is an essential human activity. It is the experience of how to create an artwork that gives expression to one's thoughts and feeling. According to Greenet et al. (2014), the productiongives students the opportunity to express themselves and show their individuality. Usually, students produce art to expand the individual expression and knowledge of design, and to discover oneself, and the universe. Stewart and Walker (2005) explain that children naturally engage in art, and they enjoy learning and how to use new materials, tools, and techniques so that they accurately express themselves. As children grow up, they learn how to make complicated decisions and judgments to achieve the impact they desire. Moreover, the satisfaction gained from producing art, children also learn through production about the artistic process. Therefore, they can better appreciate the efforts of the artists.

Dobbs (1998) defines art production as the process of responding to visual observation, thoughts, and sensations by creating works of art through thinking, imagination and applying skills using the tools and techniques of each learning experience with different materials.

Denac (2014) continues and clarifies that artistic production includes both expressive and innovative dimensions. Through the passionate aspect, the student produces work of art containing imaginary expression values, which helps the students to express their thoughts and feelings in the actual material. The teacher defines the subject and discusses it with the students as a focus on which the student builds an idea and then begins to practice skills through his work. While the creative dimension aims at enabling the student to face the particular problems through artistic practices, by studying the values, visual relationships, elements and principles of the artistic work, to develop his skills by using the tools, materials, and techniques necessary to create a variety of art forms.

The art production is a critical component of any art program. In the syllabus, art production designed for improvement proficiency exercises with instrumentation, materials, and techniques. As a student's express themselves in a visual medium, that promotes motor development. Students are encouraged to the creative use of art equipment and tools in innovative methods and to explore different media in the process of art production. They are also exposed to multimedia studies and learn the peculiarities of each media, in which they learn how to combine materials in expressive methods. (Greene, 2014; Mannathoko, 2016).

The artistic production is a field for the integrated development of the personality of the student regarding the development of perception, thinking, imagination, and expression. The student also acquires skills such as adapting raw materials, tools, artistic techniques and the methods of composition and problem solving (Houseet et al., 2009).

As a result of art practices, the student's skillswill grow and become capable of observation, thinking, dialogue, discussion, expressing a critical opinion and the ability to analyze, interpret and issue monetary judgments:

1) Understand the importance of applying the visual art and design principles in the art composition and his/her professional life.

2) Develops self-criticism, emotional empathy, and the power of observation, interpretation, and analysis of the technical composition processors. 


\subsection{Art Production Teaching Objectives}

The objectives of teaching artistic production are:

1) Acquiring the artistic skills through the technical processors.

2) Discovering the innovative methods and techniques through art practices.

3) Recognizing the nature of materials, tools and their sources.

4) Exploring the various aesthetic values through the surrounding environment.

5) Using equipment, tools, and materials in different situations.

6) Using the artistic skills and techniques which learned through art education in other sciences.

7) Expressing his/her thoughts and feelings within multiple different areas of study.

8) Developing higher thinking skills and imagination.

\subsection{Entries for Teaching Art Production}

The acquisition of technical skills and the ability to use tools and raw materials requires experimentation, perseverance, and patience. Teaching art production through DBAE cannot be done in isolation from the other three disciplines (art history, criticism, and aesthetics). Gaining the technical skills must be done during the study of artist's artworks, by analyzing their works regarding techniques, selection of materials, tools, and the impact of these technical skills on composition form in general. The teacher can interact with students during the technical production by linking this field with the other three fields of arts. To help the art education teacher to teach this discipline, the researchers suggest some ideas that can be input in teaching artistic production:

1) The students are given a set of raw materials, and the teacher encourage students to discover and explore the suitability of the raw materials for a particular idea. Then the teacher makes discussions with the students to investigate the compatibility of the plan with the chosen raw materials and tools.

2) Utilize images of artworks in a significant way. The teacher will ask the students to identify the artist's methods to solve the technical problems, to select appropriate materials, and identify the primary objective behind the artist's choice of materials and its meaning, and the most significant aspects of the work being studied.

3) Explain the impact of artworks on scientific discoveries, by reviewing the new artworks and art techniques in general.

\section{Art Production Outcomes Learning}

A summary of the most important artistic gains to the learner, the students will be able to:

1) Learn how to plan his/her creative ideas.

2) Express his/her ideas, opinions and feelings in a tangible physical way and visual forms.

3) Organize the art forms effectively in his/her artistic production.

4) Understand the visual relations between the aesthetic elements.

5) Adapt the tools, materials, techniques, equipment, handworkand artistic professions.

\subsection{History of Art}

Art and culture cannot be separated from each other because they both relate to the actions and continuation of people. Kleiner (2016) and Woodfield, (2014) defined art history as the discipline that seeks to understand different cultures and ages through studying and analyzing artworks and architecture as a means of communication. The history of art is a vital part of a serious art education program, it deals with many subjects such as painting, sculpture, architecture, design, handcrafts and other works of arts, in order to encourage humanity and sympathy by aching about the other people and societies through their visual expression (Esaak, 2017).

Art history refers to the assortment, chronology, technique and mental ideas, and seeks to learn more about a work of art and the artist who created it, before analyzing and assessing it in a social and cultural context (Stewart \& Walker, 2005). Thus, the study of the history of art means the study of different societies, and their activities carried out by man, in addition to his intellectual, cultural contributions, and his contribution to the humanity. Greer mentioned that the art history teaches us to look closely at the works of art and gives us a chance to learn about the close connections that have linked these works to the cultural and historical concepts that have emerged from them (Greer, 1984). 
History of Art discipline provide knowledge and understanding about how visual communication has evolved over time, the artist themselves and the environment in which they functioned, the changes that occur in the art field over time, the evolution of artistic style and factors that influenced them, the socio-cultural changes over time and the history of people, the differences in the way art are made from place to place and the means of expression as well as the philosophical underpinning the artists practices (Manngthoko \& Major, 2013; Merwe, 2007).This leads to a better understanding of current practices which based on the history and how art evolved over time.

\subsubsection{History of Art Teaching Objectives}

The objectives of teaching history of art through the artcurriculum to:

1) Enable students to acquire some concepts and terminology to help them in their artistic expression.

2) Analyze and compare the visual and structural features of artworks and architecture.

3) Identify and describe salient aspects of form, structure, and medium.

4) Use art historical terminology, locate artworks and architecture within a chronological framework and relate to their broader historical context.

5) Practice key elements of the art history discipline, and interpret the cultural significance of art.

6) Identify scholarly resources for research in key historical events and movements that affected the artistic production, and present findings in a coherent and persuasive form.

\subsubsection{Entries for Teaching History of Art}

The idea of connecting studio art with that of history of art began to emerge in 1979. Joining studio art with art history was enhanced through economic recovery and increased European travel by American students. Frankston (1967) stated that The study of the history of art is an essential part of superior art curricula and it is a necessary prerequisite to appreciate art and should be available at all levels. Students study the artworks accomplishments of the past and present as motivation, examples of style or technique, and as discussion topics, especiallyabout cultural, political, social, religious, and economic events and movements.

Eisner (1972) in putting forth the questions that gave impetus to the ideas of his book "Educating Artistic Vision," said that knowledge of the past was essential for future decisions. He clarified that ignorance of the past is no necessary virtue, and while knowledge of the past is no guarantee that it will notbe repeated, such knowledge does provide one useful frame of reference for looking at the present.

There are many proposals presented by art educators in teaching history of art through art education curricula such as Livi Smith, Eisner, Stephen Dobbs, Paul Getty and others. These educators stressed the importance of educating the history of art to students through:

1) Review the history of art in a structured sequence so that it shows the stages of the development of artwork and artistic movements through the chronological sequence.

2) Review history of art as a cultural entire so that art history presented as a study of artworks within a particular cultural content.

3) Review the fields of creative and artistic knowledge regarding social, cultural, political and religious aspects, which influenced the nature of art objects.

4) Display images of artworks from different cultures and epochs and ask students a set of questions as facilitators to help students to:

- Look carefully at works of art: the objective is to allow the student to think about the contents of artworks and to identify the elements of the artwork.

- Understands the concept of artist idea: the objective is to make the student feel to create this artwork.

- Talk about what they observe: the aim is to make the students describe the artwork.

- Recognize the artist achievements through his artwork: the objective is to appreciate the artist achievements in his society and to introduce the artist's accomplishments to the student.

- Discuss a variety of interpretations: the objective is to make the student provide his or her interpretationsof the artwork subject.

\subsubsection{History of Art Outcomes Learning}

After studying the art history through art curriculum, the student will be able to: 
1) Understand the sense of the past and the times in which they live.

2) Differentiate between art styles, art movements, and to analyzeand interpret the artworks.

3) Build and shape their culture, technical language, enriching their vision through the comparison and analyzing the artworks.

4) Appreciate the art and the artists' achievements.

5) Have a multiplicity vision of the different solutions to the problem, and learn about the various techniques of art.

6) Benefits from the artist's creations which considered as a source of inspiration.

7) Identifying the subject matter of works of art, their potential meaning and significance, and the larger intellectual, historical, or political trends that impact their production.

\subsection{Aesthetic}

Aesthetics means perception through sense. Day and Hurwitz (2012) defined aesthetic as the branch of philosophy that address guest questions about the nature of art and beauty; it is meaning and values, questions on our judgment of art whether good or bad and discuss notions as beautiful and ugly. Although aesthetic usually associated with art, it can also be experienced in any subject in the curriculum. Denac (2014)claims that experience in music, dancing, history, mathematics, as well as other subjects, contain the aesthetic component. On the other hand, educators like Phenix (1964) and Abbs (1994) clarifies that the aesthetic component directly associated with art experience and that it combines the affective perceptive and cognitive levels in a unique way.

Aesthetic education is an essential aspect of art education curriculum since it evaluates and heightens the experience of art. It is related directly to understand the content, emotions, and forms of art (Denac, 2014). Aesthetic education is one component of a DBAE approach to art education, and it is simply how to engage in aesthetic inquiry and make an aesthetic discussion to value a piece of art.

Teaching aesthetic in art education is achieved by raising the discussion and questions about the nature of art, and its meaning, its value and its function such as; does this art look real?; how this make you feel?; what kind of shaps do you see?; what the meaning of this artwork?; what the artist ideas or concept through this work?; and what is the purpose of this artwork in society?; and raising many philosophical questions, so that the answer leads us to differentiate between art and other aspects of human production, and to identify the differences between them, which resulted in developing standards for the evaluation of art and judgment of artwork (Carritt, 2016).

Aesthetic questioning is a valuable student experience, encouraging careful and logical thought about everyday experiences and teaching to evaluatedifferent points of view. Classrooms that encourage guided questioning promote multiple viewpoints about the artwork. The inquiry method canhave some advantages over a lecture format, by helping students to bemore active rather than passive learners and by allowing multiple perceptions tobrought into the curricula. Guided questioning ensures that the language andterms areappropriate for the age or ability levels, and promotescooperation and teamwork in finding answers for artistic problems. More advantagesto the use of inquiry can be the broader range of meanings that are achievedby analysis, frequently more diverse than that of an individual (Granger, 2016).

The benefits of using aestheticquestioninginclude positive self-esteem, group cohesiveness, and students respect themselves and each other as artists. A curriculum that provides foraesthetics will enhance the opportunities for teachers to provide students within-depth experience in visual art, offering the typical student a chanceto acquire expressive skills through progressive instruction. These forms of instruction enable all students to produce artworks that have aesthetic merit. As students develop artistic skills at various levels of achievement; they can use whatthey have learned to create works that possess greater artistic value (Loudermilk, 2002).

As a result of teaching aesthetic in art education curricula, students will learn about the aesthetic of different cultures, explore the possibilities of describing and classifying aesthetic phenomena and discuss all possible interpretations of the artwork without the prior knowledge about the artist. Through aesthetic education, the students will developaesthetic perception such as experience, evaluating, creating and expressing the beauty, developing the aesthetic sense for proportion and beautiful, developing a relationship towards nature in an interpersonal relationship (Granger, 2016).

\subsubsection{Aesthetic Teaching Objectives}

The objectives of teaching aesthetic through art education curriculaare to:

1) Notice the beautiful and aesthetic qualities such as natural wonders, shades, shapes, and pictures.

2) Induce a feeling of excitement such as joy and optimism. 
3) Develop the foundation for aesthetic judgment and evaluatingaesthetic qualities.

4) Develop a sense of aesthetic values.

5) Create aesthetic values in everyday life.

\subsubsection{Entries for Teaching Aesthetic}

1) Method of philosophical aesthetics: This technique is based on studying thinkers' opinions of aesthetics and tracking the aesthetics evolution over time, and this can be considered as an appropriate method to teach aesthetics through art education and compatible with curricula and teaching methods in general education.

2) Aesthetic search method: This method is taughtto obtain the logical and mental facts contained in the artworks such as the power of meaning, and its ability to convince the connoisseur

3) Way of experience and perception of aesthetics: which transforming the aesthetics theories into practices and activities to improve student harmony, as art can provide them with a unique and profound experiences based on the perception of visual and tangible values, as well as the development of skills, which enhance a person's ability to respond aesthetically to different contexts (Bilir-Seyhan, 2018).

4) Students select images from an internet site,and they will write about those images by using critical and aesthetic observation, they will share responses with other students.

5) Students will use actual artworks, or images of artworks, and discuss the differences between recognizing objects and seeing them from the aesthetic viewpoint. Ask students to describe an artwork and its style, use similarities and differences between artworks to discuss their techniques.

6) Each student will have a list of art vocabulary words and questions that he/she can use to conduct an aesthetic discussion.

7) Students will study in details and identify historical artwork, they will define the subject and its nature, and they will interrogate its nature and origins.

When applying DBAE in art education curriculum, students can study the aesthetics of different cultures, explore the possibilities of describing and classifying aesthetic phenomena and discuss all possible interpretations of the artwork. For example, they can discuss any artwork without the prior knowledge about the artist.

\subsubsection{Aesthetic Outcomes Learning}

After studying the aesthetic education through art curriculum, the student will be able to:

1) Gain the self- esteem, self-respect, and mutual respect.

2) Challenge by asking open-ended questions.

3) Express himself in new and different ways.

4) Learn the sharing insights with the teacher, classmates,and others.

5) Learn how to look and notice the beautiful things.

6) Participate in activities that will develop his/her creative abilities.

7) Appreciate the art and the artists' achievements.

8) Understand something as a whole by combing mind, emotion, experience, analysis, cognition and sensory.

\subsection{Art Criticism}

Art criticism is talking about art verbally or in a written form. One of the scholars of this theory, Elliott Eisner, described the importance of art criticism in schools and he stated that the future of research plane in the field of art education is unacceptable without the careful study and description, interpretation, and evaluation of what happens in the real world in classrooms (Schabmann et al., 2015). The sixties of this century was the beginning of interest in the teaching of art criticism within the curricula of art education in the United States when a seminar on art criticism held at the University of Ohio in 1966. This seminar had a significant impact on teaching the art criticism within the curriculum of art education at the secondary education level. The aim of the seminar was as aninvitation to make the history of art and its philosophy as the center for teaching art criticism to students at the American high school levels.

Art criticism in art education is to enable learners to learn the right ways to talk about artworks through discussions and dialogues between teachers and students in the classroom. The art concepts and terminologies are used to describe, interpret, and analysis works that provide students with an art culture to understand the aesthetics of the 
work and criticizes it. Day and Hurwitz (2012) defines art criticism as the art of analyzing and evaluating any approach of art with justification. They explained the purpose of art criticism is to educate students on aesthetics, appreciation, and evaluation of the artwork while facilitating analysis and critical thinking. Blackmon (2015) in her research about art criticism, and how it applied in the classroom, she presented seven types of art criticism; Feldman method 1970, Broudy method 1972, Lankford method 1984, Anderson method 1988, feminist conversation method (1970s), Modernism theory (late $19^{\text {th }}$ century), and postmodernism (late $20^{\text {th }}$ century). Blackmon (2015) clarified that Feldman method is the more widely accepted method in the classroom. This method follows four stages in order, namely, description, analysis, interpretation, andjudgment.

This method of art criticism allows students to look at themselves opinions and personal feeling about an artwork. It also will enable students with no prior knowledge of art to evaluate and critique an artwork based on the principles and the elements of art and design (Eskine \& Kozbe, 2015).

\subsubsection{Art Criticism Teaching Objectives}

The objectives of teaching art criticism through art education curriculaare to:

1) Provide students with the experiences that help to form their aesthetic perceptions.

2) Developing the observation skills, love of knowledge and creative thinking.

3) Educate students to look at the beauty and make them behave aesthetically.

4) Develop the analytical capacity associated with the application of aesthetic standards, and highlight the artwork contents from the discussion objectively.

5) Express his/her opinion and accept other opinions.

6) Help thestudent to solve other learning problems through his/her study.

7) Develop the aesthetic sensitivity of learners.

\subsubsection{Entries for Teaching Art Criticism}

Teaching art criticism through art education curricula, students know that they will learn the methods of description, interpretation, analysis, andissuance of judgments. The evaluation will be through making differentiation and comparison between good and badart and makes their final decision based on specific criteria. The following suggestion activities can be adapted for use with a less experienced student by simplifying the vocabulary and discussion questions.

1) Students will use actual artwork, and they will be asked to look carefully and examine the work by asking aesthetic questions and analyze various aspects of art, such as style, shape, color, media, texture, balance, harmony, and the relations between the composition elements. The teacher will lead the group discussion and encourage all class members to participate and to use their imagination to evaluate the artwork.

2) The teacher will display some artworks as an example and ask students to make a choice and examine whether he/she likes or dislike the art piece of their choice with identifying the negative and positive aspects that led to the judgment, based on the principles and elements of visual art and design.

3) Each student will conduct a peer evaluation through describing, analyzing, interpret and evaluate other student work in writing. Each student will get to see what other students have written about their work.

4) Students are given a work of art to critique by writing if they believe the work is successful or not and why. The teacher asks some aesthetic questions to elicit descriptive, analytical, and interpretive statements from the student.

\subsubsection{Art Criticism Outcomes Learning}

After studying the art criticism through art curriculum, the student will be able to:

1) Justify their opinions during decision-making.

2) Have the opportunity to develop his/her speaking skills by exchanging feedback with their classmates.

3) Realize what kind of art pleases most people.

4) Have skills such as artistic, linguistic and social skills that contribute positively to his/her character.

5) Develop their critical, self-reliant, problem solving, self-esteem and creativity through judgment.

6) Perceive and think critically and gaining experiencefrom artworks language.

7) Realize the multiple views of judging and experiencing an artwork, and they overcome their prior opinion. 
8) Acquire diagnostic and investigative skillsas well as the methods of analysis and interpretation.

9) Analyze the formal, technical, stylistic, compositional characteristics of works of art.

\section{Possibilities of Implementing the DBAE Theory in Jordan Art Education Curricula}

Within general education in Jordan, the curricula of art education are taught at all levels, but this curriculum did not raise the topics that lead the students' comprehensive development through their growth levels and have not developed according to the modern art education theories. This lack led to a decline in the level of learning outputs among students in art history, aesthetics, criticism and artistic production.

Implementing the DBAE in public education in Jordan will be an integrated approach to teaching art education because the DBAE theory will lead them to the comprehensive development regarding developing students' cognitive, sense, emotional aspects, artistic skills and aesthetic experience. Teaching these aspects will reflect on student's personality and their abilities to think creatively as well as using the DBAE skills in other sciences through their study levels.

It became imperative reviewing the teaching strategies and practices of art curricula in Jordanian formal school to develop the art education learning outcomes. From this point of view, the researcher proposes to include the DBAE paradigm in Jordan art education since this theory proved its effectiveness in the United States of America and other countries who were involved with the DBAE approach, because of its focus on the comprehensive development of the student. The researcher believes that the DBAE with its components is applicable in the curricula of Jordanian art education at form schools, because of their methodological divisions and the abundance of studies, references and planning methods presented by researchers in this field. Therefore, it is easy to apply this theory to the curricula of art education in Jordan for the following reasons:

1) The DBAE theory is a systematic theory divided into four disciplines (art production, art history, aesthetics, and art criticism). So there is a possibility of planing the four disciplines in different formats, which leads to the adoption and implementation of these approaches in public education, universities, and art schools, to teach students the art education in the required comprehensive manner.Also, it is like other theories taught in the other sciences, and its applications will be easy for art education teachers.

2) DBAE theory is consistent with the other methods used in teaching, providing the teacher with a theoretical material enriching the theoretical side while teaching the art education curriculum as well as a knowledge source for students.

3) Availability of some studies, references and translated books that teacher can use to provide art education classes based on this theory. In addition to benefiting from a large number of educators and academics who studied this trend in-depth.

4) The possibility to write a curriculum in general formulations to content, so that teaching art education based on the sequence of each grade level, as well as the successive stages and grades, which suit the student's age and the technical characteristics at each level.

5) The possibility of developing an academic textbook for art education thatfocuses on the four main fields as mentioned above, which includes lessons and successive activities in educational units and experiences that raise the interest of students in arts and the desire to study them.

6) Due to the comprehensiveness of this theory in developing an integrated personality of the student, it will give the art education approach an educational and professional dimension that will attract students and make them interested in art and other artistic skills. Moreover, this theory will have a tremendous educational impact on students' future regarding the development of cognitive, skills and emotional aspects.

7) The emphasis on teaching art education on the practical side makes adopting DBAE teaching theory a necessity for comprehensive development, such as how to issue judgment, analysis, and interpretation that lead to the individual cognitive integration.

8) The possibility of teaching art education to all students with different abilities. Not just those who show talent in their artistic production. This trend also cares for students with special needs, provides them with the instructions in the field of art, and helps them learn at various levels.

DBAE with its four disciplines must receive sufficient support from the Ministry of Education, educators, school principals, and those interested in curriculum development, in addition to the rehabilitation of art education teachers, and clarification of the objectives on which this theory is based on society as well. Besides, it is necessary to create an appropriate educational environment that provides the studios, equipment, materials, and tools for the learner. 


\section{Conclusion}

The curricula of art education in Jordan is mainly a studio-oriented art, though without a guideline, and it's almost devoid of contemporary artistic trends or theories especially in the public primary and secondary schools. Studio-oriented art education alone is not adequate to the needs of a multicultural society undergoing rapid change and requiring various types of input and a variety of viewpoint. Therefore, it became imperative to reconsider and improve the art education curriculum informal Jordanian schools and introduce a consistent body of knowledge, which is represented by the discipline-based art education theory (DBAE).

DBAE theory is a comprehensive approach to teaching and learningart since it is characterized with teaching art in its social, cultural, and historical context. Many educationists have viewed DBAE framework as Eisner, Greer, Barkan, Gilbert, Smoke and others to be the leading framework and the most recommended effective approach in the teaching and learning art internationally, because it integrates the studio work with the theoretical and contextual studies that includes the disciplines of art production, aesthetics, history of art, and criticism.

The DBAE theory is applicable and compatible with the current mode of learning and teaching art in Jordan because it is a comprehensive and systematic theory divided into four disciplines which is possible to be planned in a different format. It's consistent with the other methods used in teaching, the availability of educators, references, and translated articles and books about the theory, the availability of a suitable environment for the theory application.

It must be noted that art subject at schools is no less important than science, math or another school subject. Therefore, art shouldn't be taught without a guideline. Visual art curriculum should be a formal written curriculum developed for all grades levels, and it should be structured sequentially, and evaluated systematically to assess the program effectiveness and student's achievement. Considering that the DBAE in art education concerns all students, not only the gifted, it is advisable to provide the art education classes in the form of instructions that take into consideration the individual differences among the students.

\section{References}

Abbs, P. (1994). The Educational Imperative, London: Falmer Press.

Agustin, F. (2016). Discipline-Based Art Education, Art Education Case Studies 6, Retrieved from http://scholarworks.lib.csusb.edu/art-edu-study/6

Bilir-Seyhan, G., \& Ocak-Karabay, S. (2018). Early Childhood Pre-Service Teachers' Views about Visual Arts Education and Aesthetics. Eurasian Journal of Educational Research, 73, pp.131-148.

Blackmon, T. (2015). The Nature and Importance of Art Criticism and Its Educational Applications for k-12 Teachers. Phd Thesis, University of Central Florida Orlando.

Carritt, E. F. (2016). Key concepts: A guide to aesthetics, criticism and the arts in education, Routledge.

Day, T., \& Hurtwiz, A. (2012). Children and their art: Art elementary and middle schools. Boston: Wadsworth, Cengage Learning.

Delacruz, E. M., \& Dunn, P. C. (1996). The evolution of discipline-based art education. Journal of Aesthetic Education, 30(3), pp. 67-82.

Denac, O. (2014). The significance and role of aesthetic education in schooling, Creative Education, 5(19).

Dobbs, S. M. (1998). Learning in and through art: A guide to discipline-based art education, Getty Publications.

Efland, A. D. (1987). Curriculum antecedents of discipline-based art education, Journal of Aesthetic Education, 21(2), pp.57-94.

Eisner, E. (1972). Educating Artistic Vision, Macmillan Pub. Co.

Eisner, E. (1988). Discipline-Based Art Education: Its Criticisms and its Critics.Art Education, 41(6), pp. 7-13.

Esaak, S. (2017). Why You Should Study Art History-Thoughtco, Retrieved from https://www.thoughtco.com/why-should-i-study-art-history-183255.

Eskine, K. J., \& Kozbelt, A. (2015). Art That Moves: Exploring the Embodied Basis of Art Representation, Production, and Evaluation. In Aesthetics and the Embodied Mind: Beyond Art Theory and the Cartesian Mind-Body Dichotomy ,pp. 157-173, Springer, Dordrecht.

Frankston, L. (1967). Some Explorations of Effect of Creative Visual Art Experiences upon Poetry Writing Quality of $8^{\text {th }}$ Grade Students. Journal of creative behavior, 1(1), pp. 64-65. 
Granger, D. (2016). John Dewey, Robert Pirsig, and the art of living: Revisioning aesthetic education. Springer.

Greene, P., Hitt, C., Kraybill, A., \& Bogulski's, C. (2014). Arts education matters: We know, we measure it. Education Week, 34(13), 24.

Greer, W. D. (1984). Discipline-Based Art Education: Approaching Art as a Subject of Study, Studies in Art Education, 25(4), pp. 212-218.

Hassan, I., Noor, A. I. M., \& Omar, J. (2014). Teachers Perspective on the Implementation of Discipline-Based Art Education as a New Pedagogical Knowledge and Classroom Practices Approach: A Study on Art Education Malaysian Secondary School Teachers, International Conference on Fundamentals and Implementation of Education. Pascasarjana UNY.

House, V. F., Éireann, C. M., Foster, Á. V., \& Cliath, B. Á. (2009). Creativity and the Arts in the Primary School, Discussion Document and Proceedings of the Consultative Conference on Education.

Kleiner, F. S. (2016). Gardner's art through the ages: The western perspective (Vol. 1). Cengage Learning.

Loudermilk, M. L. (2002). The Use of Aesthetics in a Comprehensive Art Curriculum. Theses, Dissertations and Capstones.

Mannathoko, M. C. (2016). Discipline-Based Art Education as an Approach to Art Instruction: The Case of Standard Seven Curriculum in Botswana. International Journal of Learning, Teaching and Educational Research, 15(1).

Merwe, L. (2007). Assessment in the learning area of arts and culture. A South African perspective. The Journal of Research in Teacher Education, 14(2), pp. 51-68.

Phenix, P. (1964). Realms of Meaning: A Philosophy of the Curriculum for General Education. New York: McGraw Hill.

Schabmann, A., Gerger, G., Schmidt, B. M., Wögerer, E., Osipov, I., \& Leder, H. (2016). Where does it come from? Developmental aspects of art appreciation. International Journal of Behavioral Development, 40(4), pp. 313-323.

Stewart, M. G., \& Walker, S. R. (2005). Rethinking Curriculum in Art, Davis Publications, Inc, Worcester, MA.

Woodfield, R. (2014). Art history as cultural history: Warburg's projects. Routledge.

\section{Copyrights}

Copyright for this article is retained by the author(s), with first publication rights granted to the journal.

This is an open-access article distributed under the terms and conditions of the Creative Commons Attribution license (http://creativecommons.org/licenses/by/4.0/). 